\title{
Distal hereditary motor neuropathy type 7
}

INSERM

\section{Source}

INSERM. (1999). Orphanet: an online rare disease and orphan drug data base. Distal hereditary motor neuropathy type 7. ORPHA:139589

Distal hereditary motor neuropathy type 7 is a rare, slowly progressive genetic peripheral neuropathy characterized by distal atrophy and weakness affecting the upper limbs (with a predilection for the thenar eminence) and subsequently the lower limbs, associated with uni- or bilateral vocal cord paresis leading to hoarse voice and breathing difficulties, and facial weakness. 